\title{
A Comparison Study of foF2 Derived from Oblique Sounding Network and Vertical Ionosonde in Northern China
}

\author{
Jing Liu ${ }^{1, *}$, Wen-Yu Lou ${ }^{1}$, Xue-Min Zhang ${ }^{1}$, and Xu-Hui Shen ${ }^{2}$ \\ ${ }^{1}$ Institute of Earthquake Science, China Earthquake Administration, Beijing, China \\ ${ }^{2}$ Institute of Crustal Dynamics, China Earthquake Administration, Beijing, China
}

Received 26 May 2015, revised 3 March 2016, accepted 6 March 2016

\begin{abstract}
The China Seismo-ionospheric Ground-based Monitoring Network in Northern China was established in August 2009, consisting of 5 vertical sounding stations and 20 oblique receiving stations. We analyzed the critical frequency of the F2 region $\left(f_{\mathrm{oF}} 2\right)$ derived from vertical and oblique sounding data in this study. Our comparison results indicated that $f_{\mathrm{oF}} 2$ from vertical and oblique sounding presented very similar annual and semi-annual variation characteristics and along with the change in $\mathrm{F}_{10.7}$, the two data both enhanced after 2011. We calculated the root-mean-square error (RMSE), percent deviation (PD), and correlation coefficient $(\rho)$ between the two data, which showed good positive correlation in Beijing, Changchun, Suzhou station. Our results also demonstrated that the consistency of vertical and oblique $f \circ \mathrm{oF} 2$ was better in the summer and equinox than in winter. The correlation on calm days for all stations was better than that in the magnetic disturbance period. Our research reveals that oblique sounding data presents similar change characteristics with vertical sounding data, thus these data can be used to investigate ionospheric phenomena.
\end{abstract}

Key words: Oblique sounding data, Vertical sounding data, $f \mathrm{oF} 2$, Correlation analysis

Citation: Liu, J., W. Y. Lou, X. M. Zhang, and X. H. Shen, 2016: A comparison study of foF2 derived from oblique sounding network and vertical ionosonde in Northern China. Terr. Atmos. Ocean. Sci., 27, 933-941, doi: 10.3319/TAO.2016.03.06.01(AA)

\section{INTRODUCTION}

The ionosphere was discovered in 1901 when Marconi successfully transmitted radio signals across the Atlantic (Joly 1902). To interpret this phenomenon, Kennelly and Heaviside (Ratcliffe 1966) suggested that free electrical charges in the upper atmosphere could reflect radio waves. In 1902, the first physical theory of the ionosphere was proposed (Joly 1902). Appleton and Barnett (1925) and Breit and Tuve (1925), using radio wave sounding methods, confirmed the ionosphere's existence in the high atmosphere at nearly the same time in 1924 . This confirmation signaled the beginning of ionospheric studies.

In general, ionospheric measurement techniques can be categorized as remote and direct (in situ). The former includes vertical sounding, oblique sounding, oblique backscatter sounding, radio occultation, incoherent scatter radar, laser radar and so on. The latter involves satellite and rocket sounding (Rishbeth and Garriott 1969; Xiong et al. 1999;

\footnotetext{
* Corresponding author

E-mail: liujingeva@163.com
}

Schunk and Nagy 2009). Among these methods, vertical sounding or ionosonde is the oldest and most widely used in modern ionospheric research and space weather service. The valid ionosonde region is confined to just around the observation station. More ionopheric parameters and larger range can be obtained using incoherent scatter radar, while the operating expense is too great to maintain continuous monitoring. Satellite and rocket sounding have the capability of detecting the ionosphere in situ, however the time and location both change along the track. For monitoring range, oblique sounding and oblique backscatter sounding possess stronger ability, which has good application prospects.

Ionospheric oblique sounding has a long history. One of the most famous ionospheric oblique incident sounders is the IRIS (Improved Radio Ionospheric Sounder) system developed by Lancaster University in the UK (Arthur et al. 1996). The ionospheric oblique incident sounding network has also been built in Australia and the Russian Federation (Lynn 2008; Kim et al. 2011).

With the support of Technology and Industry for 
National Defense, PRC, China Earthquake Administration and China Research Institute of Radio wave Propagation established China Seismo-ionospheric Groundbase Monitoring Network (CSGMN) in Northern China, comprising 5 vertical sounding stations and 20 oblique sounding stations in August 2009 (http://www.sign.ac.cn/) (Fig. 1). Based on this network high resolution of ionospheric variation can reach about $100 \mathrm{~km}$ in Northern China. Xu et al. (2011) introduced routine work on seismo-ionospheric anomaly based on this network.

Zhao et al. (2010) assimilated the oblique sounding data from this net to develop the high-resolution computerized ionospheric tomography imaging method. Using CSGMN data, Zhou et al. (2013) established a real-time mapping model of $f_{\mathrm{oF}} 2$ in northern China using a newly improved neural network based on genetic algorithm optimization. For 15 - 16 July 2012, magnetic storm event, Wang et al. (2013a) found the oblique and vertical sounding data and total electron contents (TEC) observed by global position system (GPS) all had strong positive effects around the noon and sunset sectors on July 15.
This paper introduces oblique sounding data and analyzes its correlation with vertical sounding data to determine if the data can describe the ionosphere characteristics. This research is intended to provide an overview and reference for users of this net data. We introduce the data and methodology in section 2. Results and discussions are presented in section 3 . We present our brief summary in section 4 .

\section{DATA AND METHODOLOGY}

In this network, with the 5 vertical sounding stations and 20 oblique sounding stations, the maximum usable frequency (MUF) in 100 channels of radio wave transmission through the ionosphere can be obtained. All instruments in the CSGMN use GPS timing to synchronize the data between vertical transmitting stations and oblique receiving stations.

Figure 2 gives the schematic diagram for oblique sounding. $\mathrm{T}$ and $\mathrm{R}$ are the transmitting and receiving stations. $\mathrm{B}$ and $\mathrm{M}$ represent the reflection point and its projection point on the ground. TBR is the real path and TAR is the equivalent triangle path. Based on the Breit and Ture
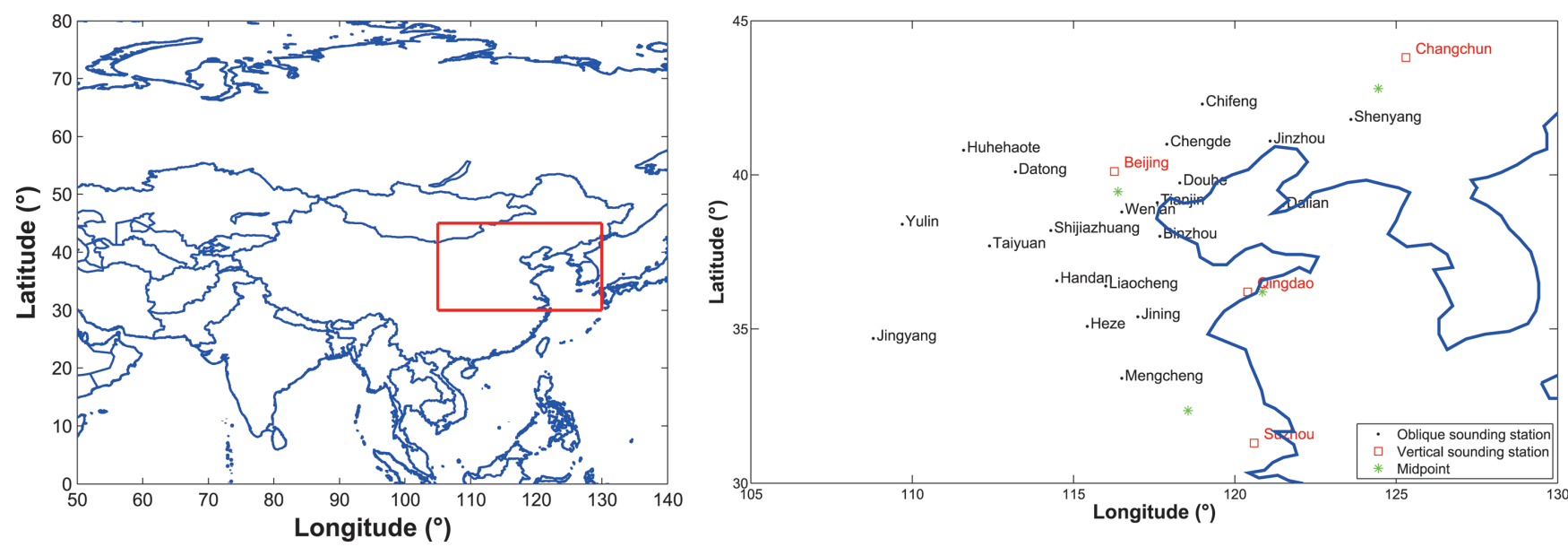

Fig. 1. The CSGMN oblique and vertical sounding stations (red squares represent vertical sounding stations, black points represent oblique sounding stations, and green asterisks represent the mid-point). (Color online only)

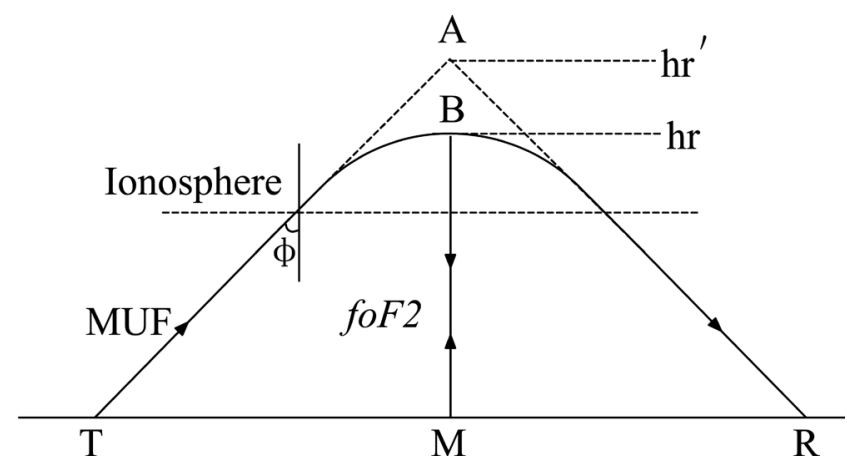

Fig. 2. Schematic diagram of oblique sounding ( $\mathrm{T}$ and $\mathrm{R}$ are the transmitting and receiving stations, $\mathrm{B}$ and $\mathrm{M}$ represent the reflection point, and its projection point on the ground). 
theorem (Xiong et al. 1999), the time of TBR and TAR path is the same. According to the Martyn equivalent theorem (Xiong et al. 1999), the virtual height of oblique sounding (hr') equals the virtual height of vertical sounding (hr). In the TAM triangle we obtain Eq. (1).

$\mathrm{MUF}=f_{\mathrm{oF}} 2 \times \sec \varphi=f \mathrm{oF} 2 \times \frac{\mathrm{TA}}{\mathrm{AM}}$

Where $\varphi$ is the incidence angle and TA and AM can be obtained using the group delay time and sphericity distance between the transmitting and receiving stations.

Ionosonde data are more reliable, so in our research, we select the nearest midpoints to the 4 vertical sounding stations (vertical sounding data of Xinxiang station were not provided in CSGMN), and study the relationship between vertical and oblique sounding data. The distance between the midpoint and vertical sounding stations was calculated using the Pythagorean Theorem, described using latitude and longitude. We found that the minimums for Beijing, Suzhou, Qingdao, Changchun stations were the midpoints of Beijing to Wen'an, Suzhou to Mengcheng, Suzhou to Jinzhou, Changchun to Shenyang respectively, with $0.66,2.3$, 0.45 , and $1.31^{\circ}$.

From the $13^{\text {th }}$ August 2009 to $31^{\text {st }}$ December 2013, 4 vertical sounding data and Wen'an, Mengcheng, Jinzhou and Shenyang oblique sounding data receiving Beijing, Suzhou, Suzhou and Changchun were collected from CSGMN. We calculated the $f_{\mathrm{oF}} 2$ median data of oblique and vertical sounding data for each day to compare the ionosphere climatologic characteristics.

\section{RESULTS AND DISCUSSIONS}

\subsection{Temporal Variation Analysis}

Figures 3 to 6 give the $f \mathrm{oF} 2$ time serial change for the 4 vertical sounding stations and their nearest reflection point. A $10.7 \mathrm{~cm}$ solar radio flux (index $\mathrm{F}_{10.7}$ ) is plotted in panel a, which indicates the major solar influence in the ionosphere. In panel $b$, the blue dots represent the oblique sounding $f \circ \mathrm{F} 2$ data and red dots represent the vertical sounding $f \circ \mathrm{OF} 2$ data. Their differences are shown in panel c. The relative change exhibited in panel $\mathrm{d}$ was also calculated using $(O-V) / V \times 100 \%(O$ and $V$ were $f \circ F 2$ of oblique and vertical sounding data).

In the 4 figures the time series change tendency of the two data were almost the same. Vertical and oblique data increased when solar activity enhanced after 2011 according to $F_{10.7}$. Many factors can affect the ionosphere, such as solar, neutral wind, tide, magnetic storm, artificial source and so on, among which solar is the main one. A lot of researchers (Liu et al. 2003, 2011; Ouattara et al. 2012) found high correlation between $f \mathrm{oF} 2$ and the number of sunspots, solar radio noise $(10.7 \mathrm{~cm})$ flux $\mathrm{F}_{10.7}$, solar EUV fluxes indicating solar activity.

There were annual and semi-annual variations in these data, with high values in April, May, September, and October. Low values were found in January and July. Similar to our results, Bravo et al. (2011) found annual and semiannual changes in the ionosphere by investigating 37-year $N_{m} \mathrm{~F} 2$ observed over Concepcion, Chile. Kawamura et al. (2002) presented that electron density at different altitudes presented semiannual variations. Yu et al. (2004) investigated the daytime F2 layer peak electron concentration $\left(N_{m} \mathrm{~F} 2\right)$ in a global ionosonde network with 104 stations. It was revealed that all global stations reached their semi-annual peaks in March/September and April/October. Focusing on the causes of these annual and semi-annual variations, Ma et al. (2003) considered that the diurnal tide in the lower thermosphere induced semiannual variations in the ionosphere. Bravo et al. (2011) considered that thermospheric wind effects and solar zenith angle changes lead to $N_{m} \mathrm{~F} 2$ larger values during the equinox than winter and summer. In order to explain the reason, Azpilicueta and Brunini (2011) developed that energy regulated by the Earth's rotation dynamo force transferred from the ring current into the atmosphere.

Same as vertical sounding data, $f_{\mathrm{oF}} 2$ observed by oblique sounding in CSGMN has the capability to capture the dominant ionospheric characteristics.

\subsection{Correlation Analysis}

Root-mean-square error (RMSE) (McKinnell 2008), percent deviation (PD), and correlation coefficient $(\rho)$ (Wang et al. 2013b; Zhou et al. 2013) were used to evaluate the correlations between vertical and oblique sounding data with Eqs. (2), (3), (4).

$$
\begin{aligned}
& \text { RMSE }=\sqrt{\frac{1}{N} \sum_{i=1}^{N}\left(f_{V i}-f_{O i}\right)^{2}} \\
& \mathrm{PD}=\frac{1}{N} \sum_{i=1}^{N} \frac{\left|f_{V i}-f_{O i}\right|}{f_{V i}} \times 100 \\
& \rho=\frac{\sum_{i=1}^{N}\left(f_{V i}-\overline{f_{V}}\right)\left(f_{O i}-\overline{f_{O}}\right)}{\sqrt{\sum_{i=1}^{N}\left(f_{V i}-\overline{f_{V}}\right)^{2}} \sqrt{\sum_{i=1}^{N}\left(f_{O i}-\overline{f_{O}}\right)^{2}}}
\end{aligned}
$$

Where $f_{V i}$ and $f_{O i}$ are the vertical and oblique $f_{\mathrm{oF}} 2$ per day and $\bar{f}_{V}$ and $\bar{f}_{O}$ represent the mean $f \mathrm{oF} 2$ for the number $N$ data.

The RMSE, PD, and $\rho$ for each year and all years were calculated first, as shown in Table 1. For the 4 stations the Qingdao station correlation was lower than that for the others, with $\rho$ less than 0.4 and PD more than $20 \%$. The reason may be that the reflection link is too long and the traveling 

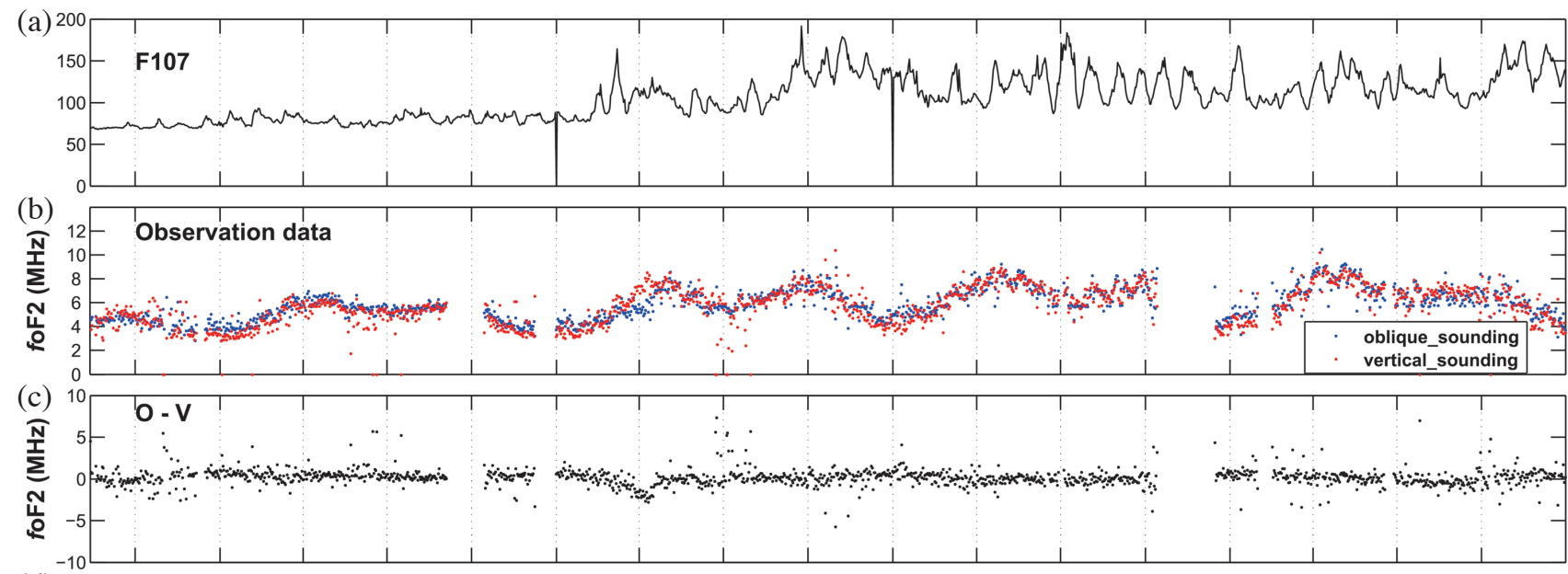

(d)

${ }_{150}-(0-\mathrm{V}) / \mathrm{V} \times 100$

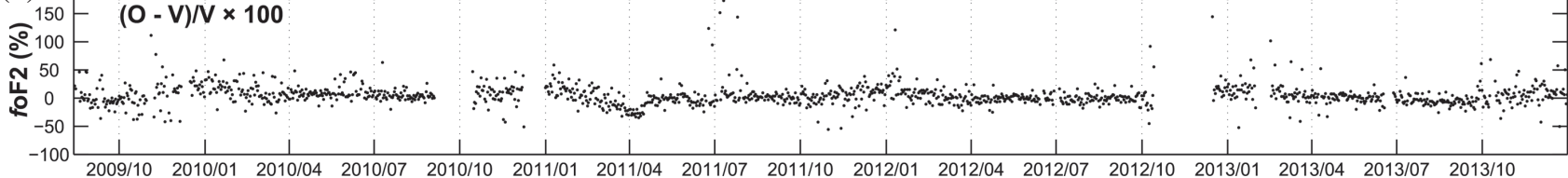

Fig. 3. Time series change in vertical and oblique sounding $f_{\mathrm{oF}} 2$ data for Beijing station; (a) index $\mathrm{F}_{107}$; (b) blue dot represents oblique sounding $f_{\mathrm{oF}} 2$ data and red dot represents vertical sounding $f \mathrm{oF} 2$ data; (c) differences in the two data; (d) relative change in the two data. (Color online only)
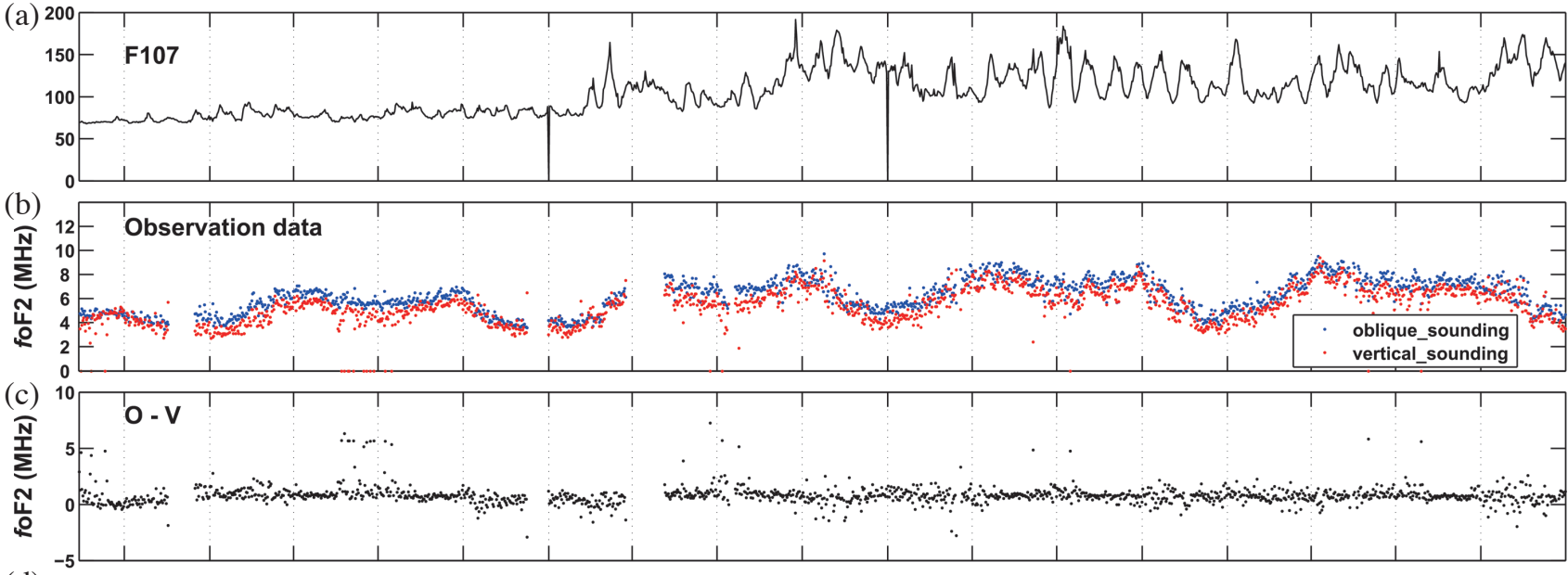

(d)

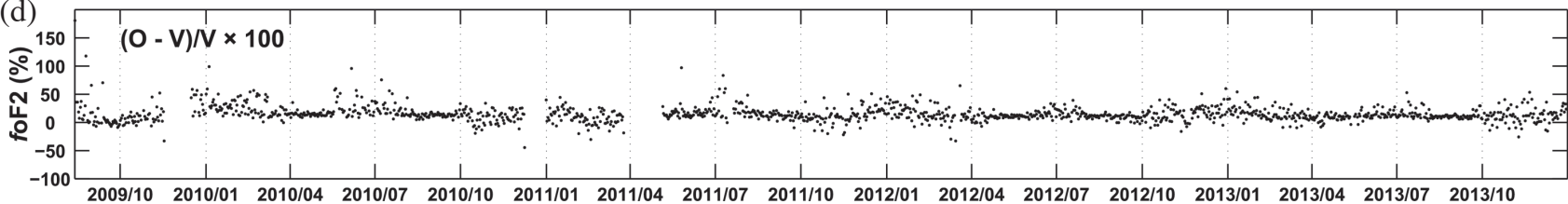

Fig. 4. Time series change in vertical and oblique sounding foF2 data for Changchun station. Subgraph introduction was same as Fig. 3. (Color online only) 


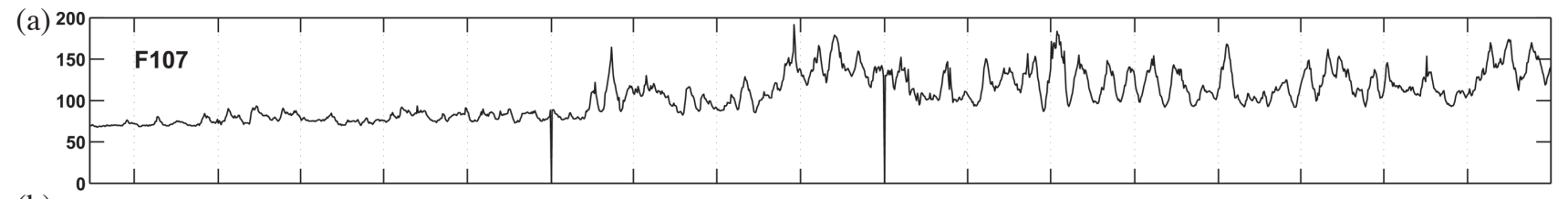

(b)
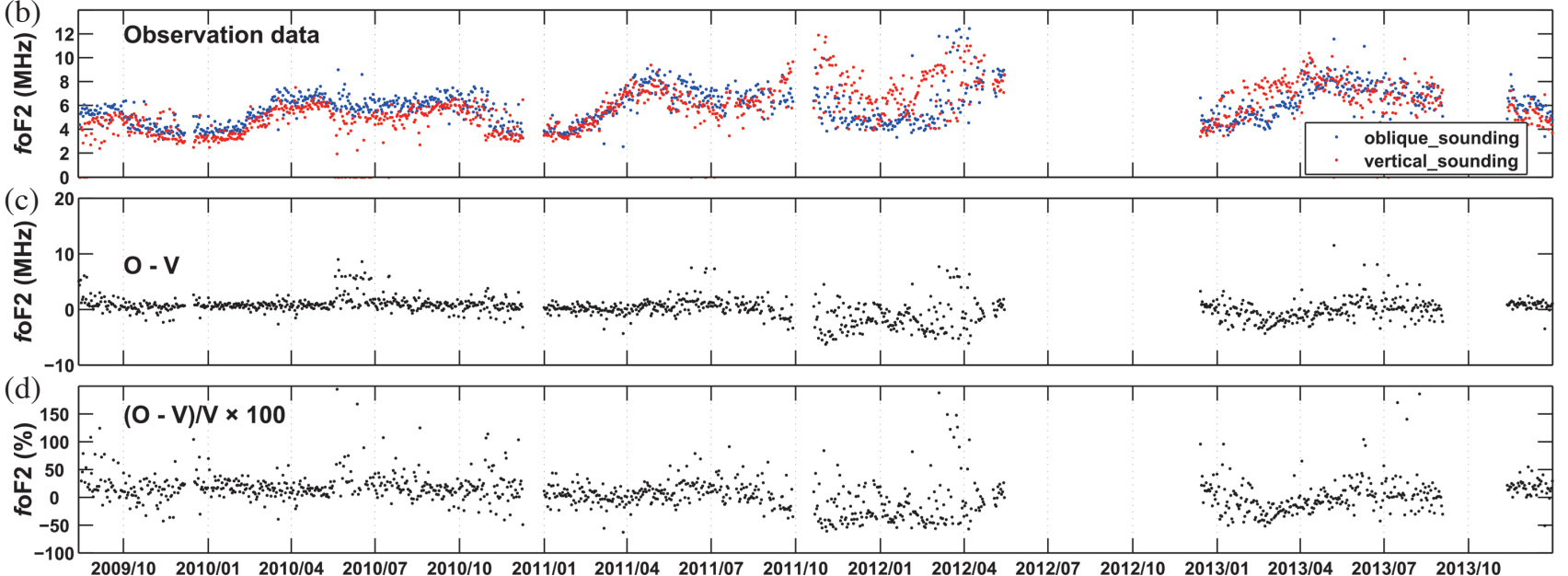

Fig. 5. Time series change in vertical and oblique sounding foF2 data for Qingdao station. Subgraph introduction was same as Fig. 3. (Color online only)

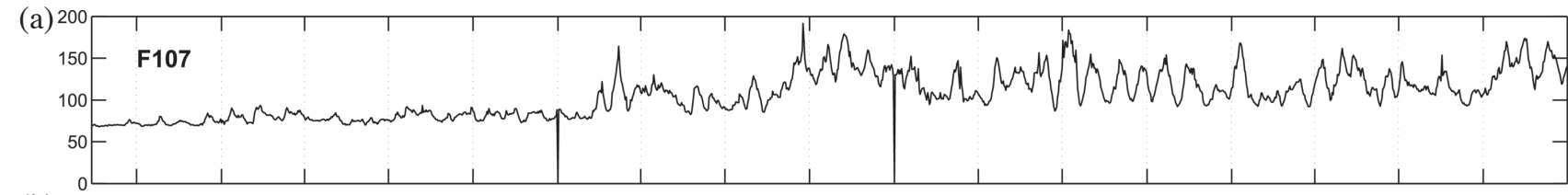

(b)
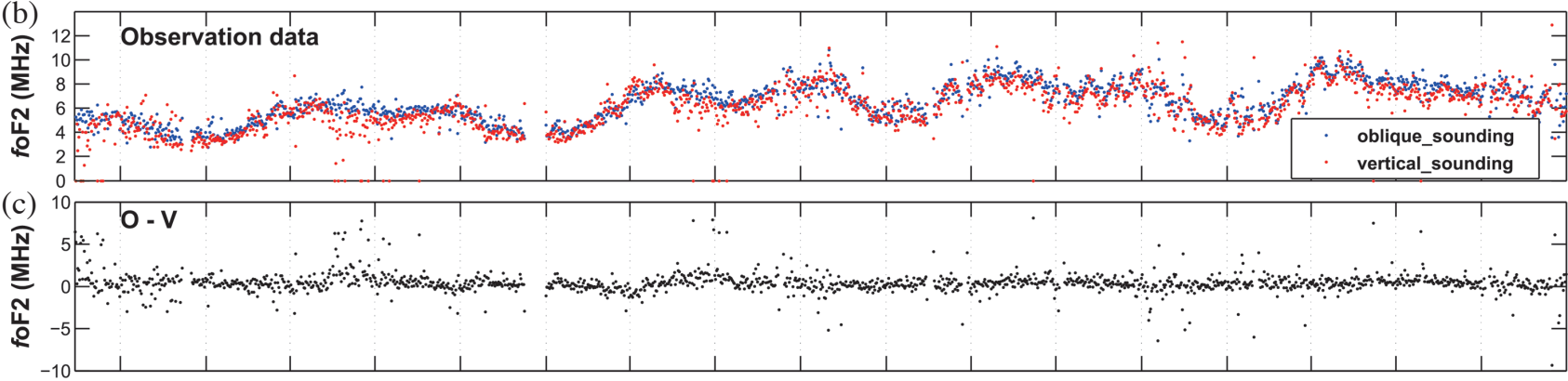

(d)

${ }_{150}-(\mathrm{O}-\mathrm{V}) / \mathrm{V} \times 100$

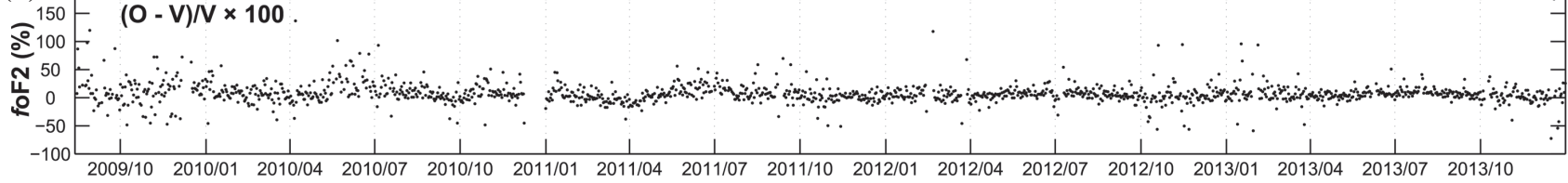

Fig. 6. Time series change in vertical and oblique sounding $f \mathrm{oF} 2$ data for Suzhou station. Subgraph introduction was same as Fig. 3. (Color online only) 
Table 1. Correlation parameters between vertical and oblique sounding $f \mathrm{oF} 2$ data in each year.

\begin{tabular}{|c|c|c|c|c|}
\hline Station & Year & RMSE (MHz) & PD (\%) & $\rho$ \\
\hline \multirow{6}{*}{ Beijing } & 2009 & 1.2128 & 17.0631 & 0.0521 \\
\hline & 2010 & 0.9924 & 13.5887 & 0.6547 \\
\hline & 2011 & 1.2116 & 13.0453 & 0.6558 \\
\hline & 2012 & 0.8120 & 9.8059 & 0.8154 \\
\hline & 2013 & 1.0654 & 11.3491 & 0.7018 \\
\hline & $2009-2013$ & 1.0574 & 12.4282 & 0.7598 \\
\hline \multirow{6}{*}{ Changchun } & 2009 & 1.1304 & 16.8031 & 0.1612 \\
\hline & 2010 & 1.4169 & 19.3512 & 0.5680 \\
\hline & 2011 & 1.1267 & 16.6315 & 0.8011 \\
\hline & 2012 & 1.0027 & 15.4081 & 0.8907 \\
\hline & 2013 & 1.0175 & 14.1007 & 0.8601 \\
\hline & $2009-2013$ & 1.1482 & 16.3581 & 0.8352 \\
\hline \multirow{6}{*}{ Qingdao } & 2009 & 1.5391 & 23.6960 & 0.1554 \\
\hline & 2010 & 1.8623 & 21.7079 & 0.3475 \\
\hline & 2011 & 1.9013 & 18.7614 & 0.3262 \\
\hline & 2012 & 2.8722 & 32.4477 & 0.1182 \\
\hline & 2013 & 1.9151 & 21.7584 & 0.1950 \\
\hline & $2009-2013$ & 1.9941 & 22.3396 & 0.3527 \\
\hline \multirow{6}{*}{ Suzhou } & 2009 & 1.8402 & 24.3764 & -0.1366 \\
\hline & 2010 & 1.4460 & 16.5430 & 0.3184 \\
\hline & 2011 & 1.2701 & 10.9367 & 0.6801 \\
\hline & 2012 & 1.1519 & 10.3683 & 0.7059 \\
\hline & 2013 & 1.2662 & 10.7528 & 0.6209 \\
\hline & $2009-2013$ & 1.3412 & 13.1312 & 0.7295 \\
\hline
\end{tabular}

ionospheric disturbances (TID) may make the MUF variation at oblique sounding paths, which will disagree with the vertical sounding data (Ryabova et al. 2014). CSGMN has received data since the $13^{\text {th }}$ of August 2009, so the small sample in 2009 made the relevance low for each station. Except for $\rho$ in 2009 for the Suzhou station, the others all revealed a positive correlation between the vertical and oblique sounding data. $\rho$ was $0.7598,0.8352,0.7295$ at the Beijing, Changchun, and Suzhou stations from 2009 - 2013, respectively, which meant significant correlation between the two data. Figure 7 shows most of the PD are lower than 20\%, with RMSE less than $1.5 \mathrm{MHz}$ and except for the Qingdao station, the absolute deviations (vertical data minus oblique data) had a single peak less than ' 0 ' (Fig. 8), which meant the correlation between the two data was good. Furthermore, the oblique data is a little bigger than the vertical data.

The more active the sun is, the better the relevance is. At the Beijing, Changchun, and Suzhou stations $\rho$ for 2011, 2012, 2013, are higher than that of 2010, while PD is lower. Solar activity is the main factor in the ionosphere, so when the sun acts drastically, $f \mathrm{oF} 2$ will increase all over the world.
Different from local changes, the ionospheric parameters in this situation may change synchronously over a large area; therefore, the coefficient for the same point may be better. Higher $f \mathrm{oF} 2$ may make the denominator bigger in Eq. (3), which can be used to explain PD decreasing.

Secondly, we divided all of the months into equinox (March, April, September, October), winter (November, December, January, February), summer (May, June, July, August), in order to analyze the seasonal change characteristics of the correlation between the vertical and oblique sounding data. The $\rho$ of each season was calculated for 4 stations using Eq. (4). From Fig. 9 it can be seen that the tendency for $\rho$ in Beijing and Qingdao stations was almost the same, having a relatively high value for summer. At the Changchun station the correlation between the vertical and oblique sounding data was better for the equinox period. At Suzhou station the equinox days were a little higher compared to the winter and summer days. A winter anomaly has been reported in the ionosphere by many researchers (Rishbeth and Müller-Wodarg 2006; Lee et al. 2011), during which the $f_{\mathrm{oF}} 2$ or $N_{m} \mathrm{~F} 2$ may be greater in winter than in summer. This characteristic may make the ionosphere change, so the correlation between the two data observed using different instruments was lower in winter than in other seasons.

We analyzed RMSE, PD and $\rho$ during calm and magnetic storm days $(K p>3.0$ and $D$ st $\leq-30 \mathrm{nT})$ using Eqs. (2), (3), and (4) for these 4 stations from 2009 to 2013. As shown in Table 2, for all stations, the calm days had higher $\rho$ and lower RMSE than magnetic storm days. This means the former correlation between the vertical and oblique sounding data was better than the latter one, but the former PD was a little bigger than the latter one. On calm days the ionosphere changes slow with time, so the difference between the two data is small. This result was also found in Zhou et al. (2013) between the observation data and predicted data. If the ionosphere is calm the electron density may show a lower level than on magnetic storm days. It can therefore be understood that PD displays higher value on calm days according to lower $f \mathrm{oF} 2$ in Eq. (3).

\section{CONCLUSIONS}

Based on the CSGMN oblique and vertical sounding data we analyzed the temporal changes and correlation between the $f_{\mathrm{oF}} 2$ derived from oblique and vertical sounding data. The major conclusions are as follows:

(1) Along with the changes in index $F_{10.7}$, the vertical and oblique sounding data were both enhanced after 2011 and also displayed annual and semi-annual variation characteristics. Except for a few days the $f \mathrm{oF} 2$ differences between the two data were almost $\pm 1.5 \mathrm{MHz}$, less than $20 \%$ in relative change.

(2) The RMSE, PD, and correlation coefficient $(\rho)$ were used to evaluate the correlations between vertical and 

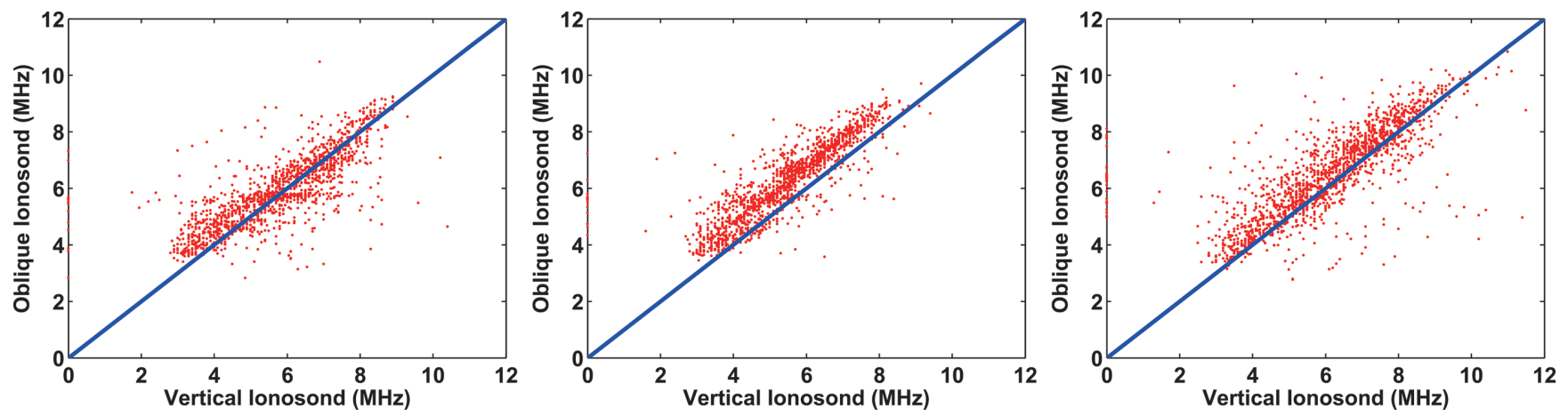

Fig. 7. Correlation between vertical and oblique sounding foF2 data from 2009 to 2013 in Beijing (left), Changchun (middle), Suzhou (right) stations. (Color online only)
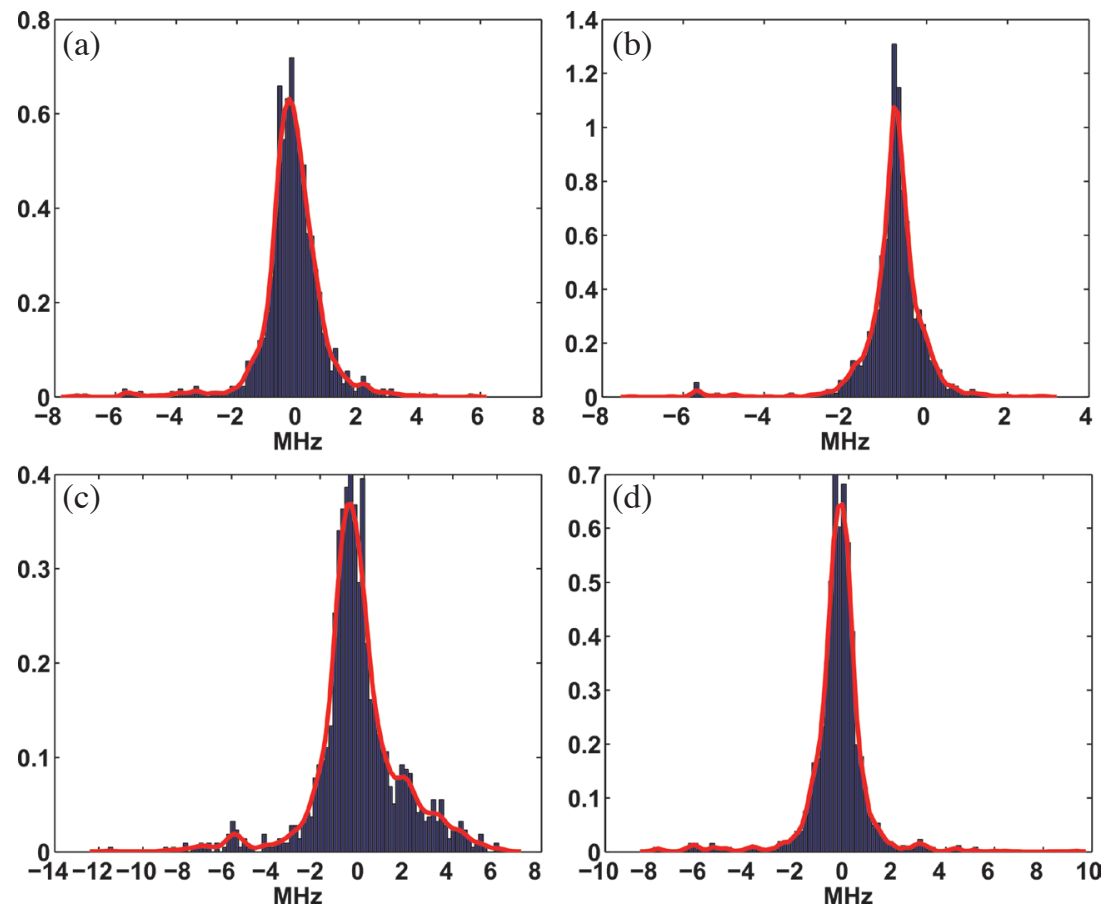

Fig. 8. Absolute deviation between vertical and oblique sounding foF2 data from 2009 to 2013 for Beijing (a), Changchun (b), Qingdao (c), Suzhou (d) stations. (Color online only)

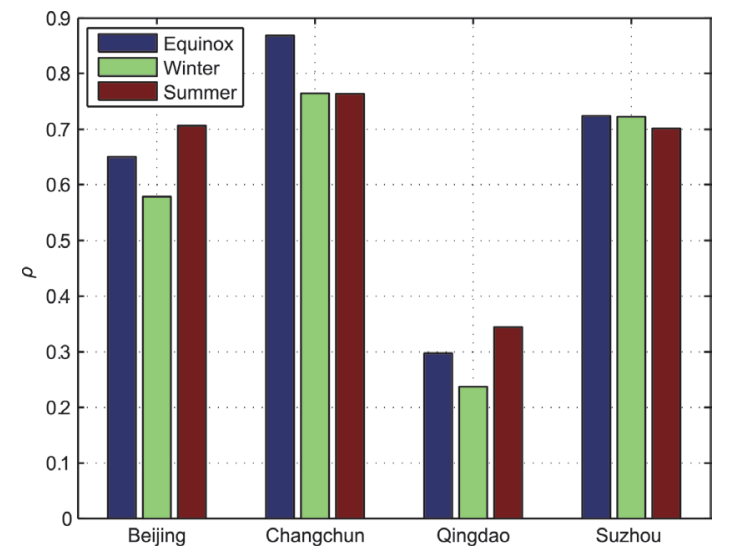

Fig. 9. $\rho$ of equinox, winter, summer from 2009 to 2013 for 4 stations. (Color online only) 
Table 2. Correlation parameters between vertical and oblique sounding $f_{\mathrm{oF}} 2$ data in calm and magnetic storm days.

\begin{tabular}{c|cccc}
\hline Station & Condition & RMSE $($ MHz) & PD $(\boldsymbol{\%})$ & $\boldsymbol{\rho}$ \\
\hline \multirow{2}{*}{ Beijing } & Magnetic storm days & 1.2302 & 11.6483 & 0.5998 \\
& Calm days & 0.9737 & 12.7638 & 0.8057 \\
\hline \multirow{2}{*}{ Changchun } & Magnetic storm days & 1.2794 & 15.8931 & 0.7270 \\
& Calm days & 1.0900 & 16.5486 & 0.8647 \\
\hline \multirow{2}{*}{ Qingdao } & Magnetic storm days & 2.2773 & 22.3917 & 0.1634 \\
& Calm days & 1.8700 & 22.3190 & 0.4028 \\
\hline \multirow{2}{*}{ Suzhou } & Magnetic storm days & 1.4599 & 12.5065 & 0.6298 \\
& Calm days & 1.2892 & 13.3879 & 0.7529 \\
\hline
\end{tabular}

oblique sounding $f_{\mathrm{oF}} 2$ data. It was found that besides the Qingdao station, the two data expressed positive correlation, and $\rho$ was $0.7598,0.8352,0.7295$ at the Beijing, Changchun, and Suzhou stations, respectively, from 2009 to 2013. This is a significant correlation.

(3) The correlations in the summer and equinox period were better than those in winter. Furthermore, for all stations, calm days had higher $\rho$ and lower RMSE than magnetic storm days, which means the correlation for calm days was a little better.

The analysis in this paper reveals that compared with the CSGMN vertical sounding data, the observation accuracy of oblique sounding data is precise enough to investigate the ionosphere changes caused by solar, magnetic storms, atmospheric oscillation et al. and develop ionospheric model, tomography imaging method technology.

Acknowledgements This work was funded by International Cooperation Project (2014DFR21280), Basal Research Fund (2016IES0306), National Natural Science Foundation of China (41511130032), and National High-Tech Research and Development Program of China (863 Program) (2012AA121004). The authors acknowledge China Seismoionospheric Ground-based Monitoring Network for providing the vertical and oblique sounding data.

\section{REFERENCES}

Appleton, E. V. and M. A. F. Barnett, 1925: Local reflection of wireless waves from the upper atmosphere. Nature, 155, 333-334, doi: 10.1038/115333a0. [Link]

Arthur, P. C., E. C. Thomas, P. S. Cannon, E. M. Warrington, N. C. Davies, and J. Thornhill, 1996: A GPS locked oblique ionosonde system using IRIS. IEE Colloquium on Remote Sensing of the Propagation Environment, IEE, Savoy Place, London WCPR OBL, UK, doi: 10.1049/ic:19961178. [Link]

Azpilicueta, F. and C. Brunini, 2011: A new concept regarding the cause of ionosphere semiannual and an- nual anomalies. J. Geophys. Res., 116, A01307, doi: 10.1029/2010JA015977. [Link]

Bravo, M. A., A. J. Foppiano, and R. A. del Río, 2011: Longterm dependencies of annual and semiannual components of NmF2 over Concepción. Open Atmos. Sci. J., 5, 2-8, doi: 10.2174/1874282301105010002. [Link]

Breit, G. and M. A. Tuve, 1925: A radio method of estimating the height of the conducting layer. Nature, 116, 357, doi: 10.1038/116357a0. [Link]

Joly, J., 1902: Mr. Marconi's results in day and night wireless telegraphy. Nature, 66, 199, doi: 10.1038/066222c0. [Link]

Kawamura, S., N. Balan, Y. Otsuka, and S. Fukao, 2002: Annual and semiannual variations of the midlatitude ionosphere under low solar activity. J. Geophys. Res., 107, doi: 10.1029/2001JA000267. [Link]

Kim, A. G., K. G. Ratovsky, V. V. Khakhinov, and V. I. Kurkin, 2011: The project of monitoring the ionosphere over Russian Federation by means of digital FMCW ionosondes network. 2011 XXXth URSI General Assembly and Scientific Symposium, Istanbul: URSI, G04-6, doi: 10.1109/URSIGASS.2011.6050899. [Link]

Lee, W. K., H. Kil, Y. S. Kwak, Q. Wu, S. Cho, and J. U. Park, 2011: The winter anomaly in the middle-latitude $F$ region during the solar minimum period observed by the Constellation Observing System for Meteorology, Ionosphere, and Climate. J. Geophys. Res., 116, A02302, doi: 10.1029/2010JA015815. [Link]

Liu, J.Y., Y.I.Chen, and J. S.Lin, 2003: Statistical investigation of the saturation effect in the ionospheric foF 2 versus sunspot, solar radio noise, and solar EUV radiation. J. Geophys. Res., 108, doi: 10.1029/2001JA007543. [Link]

Liu, L., Y. Chen, H. Le, V. I. Kurkin, N. M. Polekh, and C. C. Lee, 2011: The ionosphere under extremely prolonged low solar activity. J. Geophys. Res., 116, A04320, doi: 10.1029/2010JA016296. [Link]

Lynn, K. J. W., 2008: Oblique sounding in Australia. Available at http://www.ips.gov.au/IPSHosted/INAG/web62/obliqu 1.htm.

Ma, R., J. Xu, and H. Liao, 2003: The features and a possible mechanism of semiannual variation in the peak electron density of the low latitude F2 layer. $J$. Atmos. Sol.-Terr. Phys., 65, 47-57, doi: 10.1016/S13646826(02)00192-X. [Link]

McKinnell, L. A., 2008: Using neural networks to determine the optimum solar input for the prediction of ionospheric parameters. Adv. Space Res., 42, 634-638, doi: 10.1016/j.asr.2007.11.008. [Link]

Ouattara, F., D. A. Gnabahou, and C. A. Mazaudier, 2012: Seasonal, diurnal, and solar-cycle variations of electron density at two West Africa equatorial ionization anomaly stations. Int. J. Geophys., 2012, doi: 10.1155/2012/640463. [Link] 
Ratcliffe, J. A., 1966: The ionosphere and the engineer. Electronics and Power, 12, 381-382, doi: 10.1049/ ep.1966.0304. [Link]

Rishbeth, H. and O. K. Garriott, 1969: Introduction to Ionospheric Physics, Academic Press, New York, 344 pp.

Rishbeth, H. and I. C. F. Müller-Wodarg, 2006: Why is there more ionosphere in January than in July? The annual asymmetry in the F2-layer. Ann. Geophys., 24, 3293-3311, doi: 10.5194/angeo-24-3293-2006. [Link]

Ryabova, M., A. Chernov, V. Ivanov, D. Ivanov, and N. Riabova, 2014: The role of the TID in the sunrise-sunset effects of diurnal variations of the characteristics of the residual components of the MUF. 40th COSPAR Scientific Assembly, Abstract C0.2-29-14.

Schunk, R. and A. Nagy, 2009: Ionospheres: Physics, Plasma Physics, and Chemistry, Cambridge University Press, $628 \mathrm{pp}$.

Wang, M., W. Lou, P. Li, X. Shen, and Q. Li, 2013a: Monitoring the ionospheric storm effect with multiple instruments in North China: July 15-16, 2012 magnetic storm event. J. Atmos. Sol.-Terr. Phys., 102, 261-268, doi: 10.1016/j.jastp.2013.05.021. [Link]

Wang, R., C. Zhou, Z. Deng, B. Ni, and Z. Zhao, 2013b: Predicting $f_{o} \mathrm{~F}_{2}$ in the China region using the neural networks improved by the genetic algorithm. $J$.
Atmos. Sol.-Terr. Phys., 92, 7-17, doi: 10.1016/j. jastp.2012.09.010. [Link]

Xiong, N. L., C. C. Tang, and X. J. Li, 1999: Introduction to the Ionosphere Physics, Wuhan University PRESS, 354-433. (in Chinese)

Xu, T., J. Wu, Z. Zhao, Y. Liu, S. He, J. Li, Z. Wu, and Y. Hu, 2011: Monitoring ionospheric variations before earthquakes using the vertical and oblique sounding network over China. Nat. Hazards Earth Syst. Sci., 11, 1083-1089, doi: 10.5194/nhess-11-1083-2011. [Link]

Yu, T., W. Wan, L. Liu, and B. Zhao, 2004: Global scale annual and semi-annual variations of daytime $\mathrm{NmF} 2$ in the high solar activity years. J. Atmos. Sol.-Terr. Phys., 66, 1691-1701, doi: 10.1016/j.jastp.2003.09.018. [Link]

Zhao, H. S., Z. W. Xu, J. Wu, and Z. G. Wang, 2010: Ionospheric tomography by combining vertical and oblique sounding data with TEC retrieved from a triband beacon. J. Geophys. Res., 115, A10303, doi: 10.1029/2010JA015285. [Link]

Zhou, C., R. Wang, W. Lou, J. Liu, B. Ni, Z. Deng, and Z. Zhao, 2013: Preliminary investigation of real-time mapping of $f_{o} F_{2}$ in northern China based on oblique ionosonde data. J. Geophys. Res., 118, 2536-2544, doi: 10.1002/jgra.50262. [Link] 